Case Reports

\title{
Skills, Schools and Employability: Developing Skill Based Education in Schools of India
}

\author{
${ }^{1}$ Prativa Mahapatra and ${ }^{2}$ Sandeep Satapathy \\ ${ }^{I}$ Department of Education, Gadibrahma Women's College, Kaduapada, Jagatsinghpur, India \\ ${ }^{2}$ Department of Biological Sciences, Indian Institute of Science Education and Research, Bhopal, India
}

\author{
Article history \\ Received: 02-12-2015 \\ Revised: $13-05-2016$ \\ Accepted: 25-05-2016 \\ Corresponding Author: \\ Sandeep Satapathy \\ Department of Biological \\ Sciences, Indian Institute of \\ Science Education and \\ Research, Bhopal, India \\ Email: satapathys@live.in
}

\begin{abstract}
Skill Education in India needs more attention as like the general education imparted at schools. Irrespective of the stage of schooling (primary, secondary and higher secondary) a rise in the employability and industrial skills, ensures a better and productive human resource. With the aim of increasing the employability of the youth it is essential to develop a thorough understanding of the existing infrastructure and academic curriculum of schools and polytechnic institutes in India. This paper critically analyses the pattern and scopes of vocational education in India and how the same can be seamlessly amalgamated with the school curriculum.
\end{abstract}

Keywords: Vocational, Primary Schools, Skills, Employment, Economic Development

\section{Introduction}

India represents a population with wide range of socio-economic diversities and an uneven distribution of both natural and man-made resources. Human resource development and skill mapping have been lately being appreciated for their major contribution to a nation's economical, social and administrative progress. Thus it is essential to identify, develop and retain skills in developing nations with rapidly changing economic scenario as like that of India (NSDC, 2005). Skill refers to a broader set of aptitude but is mostly understood as marketable skills and the interest in developing these skills gets limited to specific groups of people (Burrell and Anderson, 2008).

Usually the research on skill development and employability aptitude focuses on the people who fall under the age group of 23-40 years, as are considered to be "market ready" and promising candidates for most jobs and services (Burrell, 2006a). Undoubtedly the education qualifications, employment experiences and skills acquired by this age bestows a unique advantage to this age group. However this has also restricted our vision of skill development to a certain age group with limited inclusiveness of the youth below 23 years.

Such a limited classification and an idiosyncratic focus on a particular age group have significantly restricted the research on skill development in schools. It also restricts our aim of achieving a targeted program for early stage skill development and thus we aim to bridge this knowledge gap by extrapolating skill development issues among school children of India (Burrell, 2006a).

\section{Problem with Delayed Efforts for Skill Development}

There has been a consensus that the delivery and effective incorporation of skill development lesson by adults (23-40 years) are limited by the availability of focussed time for learning new skills with dedication as the responsibilities of family, professional work burden and personal priorities take their toll (Burrell, 2006b). This leads to a disinterested classroom, ineffective practical learning and impaired implementation ability at work place (Burrell, 2006b). The expected impact of these lessons gets diluted and the immediate goal of such students is mostly for escalating their professional career or pay package (Burrell, 2006b). Although these sum up to be the most generous expectations of employees and job seekers but the real goal of enhancing human resource remains unachieved in long run (Dhawan, 2004).

In addition most professionals or job seekers of the age group of 23-40 years have a specific demand to devote least possible time for their training as they aim to start their professional career as early as possible. Although this renders most youth of a country to be economically active and self-reliant, at the same time this also emphasizes that through a very short course module over a restricted time period several broader skills cannot be imparted (Dhawan, 2004). In addition, the choice of special technical streams during the training period gets influenced by jobs, salary and personal reasons. The candidate is also seen to be taking decision not from his experience with the field rather from his brief understanding of the career prospects 
(Dhawan, 2004). In several instances the outcome has been early job dissatisfaction, growing disinterest among the employees and the lack of effective employeremployee coordination. These indeed result in declining productivity, output and financial returns of company, firms and services (Haseloff, 2005).

Another scientific reason contrary to the ability of learning employable skills is the decline in analytical ability to learn new things with age. This implies the sooner harder lessons are taught, the better it is (Haseloff, 2005). However the authors here do not advocate for tough and impractical lessons for school children but rather a systematic, appropriate and gradual course framework, which includes equal importance for the skill development lessons. The basic approach for such a coursework should range both theoretical and practical lessons (Kaushik and Singh, 2004). A similar study conducted on learning of non-native languages or creative skills showed that the ability to learn these skills is greater with children at their lower age, given that have thorough and frequent exposure to these during their daily activities (Kaushik and Singh, 2004).

So, these facts support our claim that for any creative and technical skill it is better to have an early experience and exposure in a frequent and systematic way, which ultimately yields in improved skills and efficiency (Kiri and Menon, 2006). Therefore, we promote the idea of including skill based education and practical training among school students ranging from primary schools and ranging up to higher secondary schools (Kumar, 2004). Subsequently, the choice remains with the students whether they pursue their professional education in a vocational stream or choose to take up further higher education in engineering, medicine, law, science and humanities (Kumar, 2004). This will result in an overall reinforced human resource and a better incorporation of skills when imparted from childhood.

\section{India and Schools}

The statistical analysis of enrollment in Indian schools and the focus on development of skills has helped to substantiate our emphasis for skill development courses in India. The selected educational statistics report published by Ministry of Human Resource Development (MHRD) in 2005-06 estimates the present enrollment of 227 million in 1.3 million schools in India. These schools range from primary, secondary to higher secondary schools (Fig. 1). The sectoral division of these schools is as follows: Primary (class I to class V), secondary (class VI to class VIII) and higher secondary schools (class IX to class XII) (Kuriyan et al., 2006).

Of the total enrollment of students across all the three levels of schools, primary schools account for about $60 \%$ (Fig. 1). In addition given the high drop-out ratio of students at primary and secondary level, our focus for early introduction of skill based courses and vocational training needs start from these levels (i.e., primary and secondary levels) (Kuriyan et al., 2006). A major challenge is in designing an appropriate course curriculum for these students at primary and secondary schools, so that the introduction of skill based education is not merely an academic burden but adds to their aptitude and personality development. This calls for more academic and administrative involvement, discussion among scholars and policy makers and a pilot project for introduction and evaluation of skill based/vocational courses in schools (Lee, 1999).

There has been a net rise in the national gross enrollment ratio and decline in the gross dropout ratio in India over the past decade. Such a weighing between enrollment and drop-out rates has witnessed a Compounded Annual Growth Rate (CAGR) 2013-14 of approx $3.3 \%$ (Fig. 2). A promising figure is seen among the sectorial classification of the CAGR where secondary and higher secondary have a higher weight age of CAGR to the net national CAGR with figures as 4.0 and $5.4 \%$ respectively (Fig. 2) (NSDC, 2005). This gives an outlook of changing enrollment among schools and the rising interest in school education. To make this whole picture seem more economically rewarding and personality boosting, it is equally important to incorporate vocational and skill based education at all these levels (NSDC, 2005).

The contribution of vocational education stream to the gross enrollment is indeed low as per the report of 2005-06 (Selected education statistics, MHRD, Govt. of India). The program of vocational education has a current enrollment of only 22,000 students at the national level and when considered for all the students registered with National Institute of Open Schooling (NIOS) (Fig. 3) (NSDC, 2005) this accounts for maximum total of 3 lakhs students among the 227 million gross enrolled students in India (Fig. 3). The NIOS is the parent body offering this recognised vocational education program in India (Lee, 1999).

For a statistical analysis of the available infrastructure and scope for pursuing technical and vocational education (ITIs and ITCs), there are now 1,274 polytechnic institutes and 1,562 technical institutes (engineering, medicine and architecture) among the 20,769 total higher education institutes in India (NSDC, 2005; Lee, 1999).

This also shows the severe deficit in the number of institutes offering vocation education and thus collaborating with the exiting vocational institutes for the largely scattered primary and secondary schools in India will be challenge. Capacity building and infrastructural reinforcement along with more opening of polytechnic schools and colleges across the country will help to fulfill the dream of imparting skill education to school students. 
Total enrollment in different sectors of schools in 2005-06

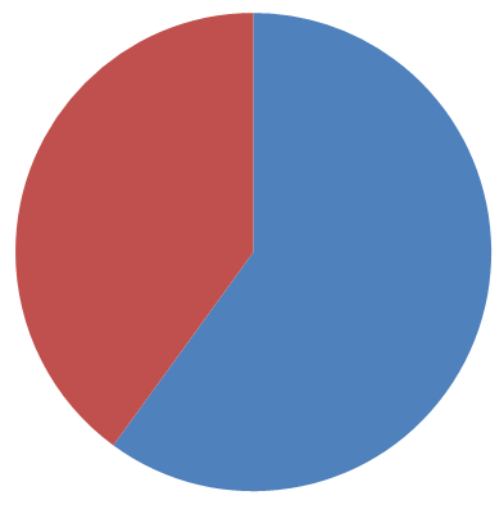

- Primary schools

- Secondary and Higher secondary schools

Fig. 1. Total enrollment in schools for 2005-06 was accounted for 227 million of which primary schools accounted for approx. 136 million (60\%) whereas the secondary and higher secondary schools accounted for the remaining 40\% (approx. 91 million)

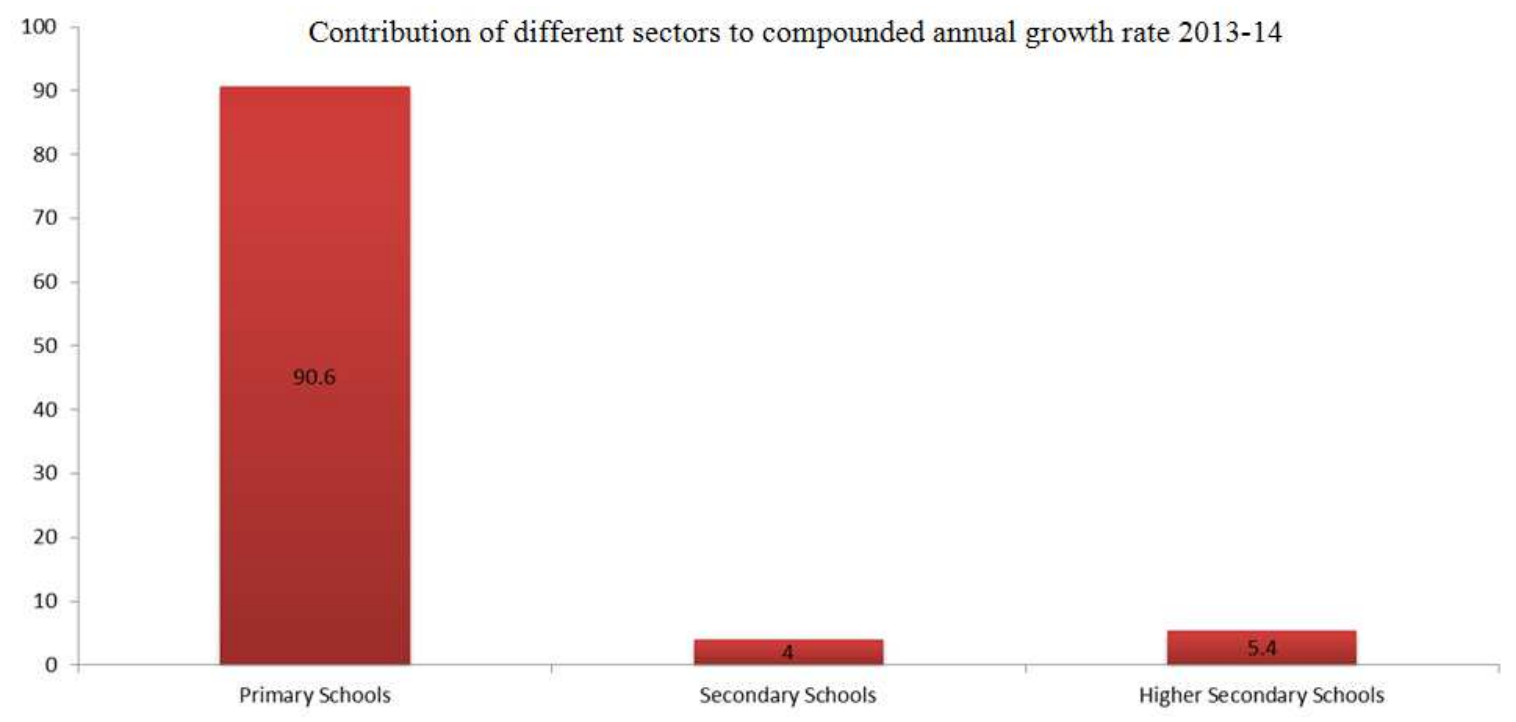

Fig. 2. Contribution of different sectors to a rising Compounded Annual Growth Rate (CAGR) during 2013-14. Of this primary schools contribute the highest at around $90.6 \%$ followed by higher secondary schools at $5.4 \%$ and secondary schools at $4 \%$

\section{Comparison of students registered under vocational education stream w.r.t total enrollment}

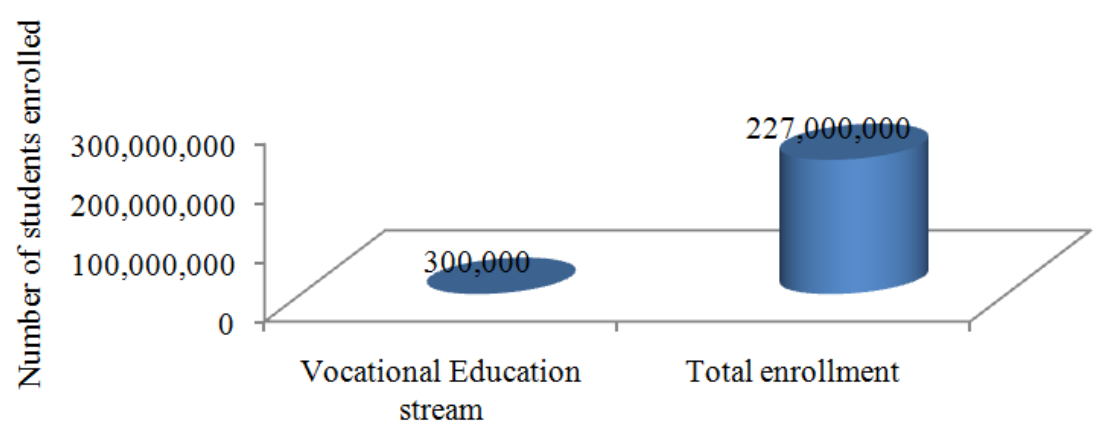

Fig. 3. Comparison of students registered under vocation education stream (National Institute of Open Schooling) with respect to the total enrollment of students in 2005-06 


\section{Schools and Skills}

School education in India spans mostly between 10-12 years of age and accounts for the initial phase of academic and personal training of an individual (Licker, 2001). With the growing competitiveness for jobs, higher education and employability the course curriculum has often been neglected in terms of incorporation of skill based and vocational education. Interestingly, there is a growing demand for the introduction of more practical courses like disaster preparedness, sustainable science, yoga, Environmental education, Vocational Courses like Fitter technology, painter, diesel mechanic etc. in addition to physical and sports education (Licker, 2001).

Schools in eastern India, especially from Bihar, Odisha and West Bengal are mostly lacking with the basic infrastructure for running such courses. In comparison, schools in West Bengal have been leading the trend of education in zone with comparative levels of schools in Odisha and Bihar. So, the need for more financial grants to schools, recruitment of more skilled teachers and integration of schools and polytechnic institutes can ease the process of delivery vocational education in schools (Pohjola, 2002).

\section{Administrative Set Up for Vocational Education in India}

The current administrative regulation of vocational and skill based education is regulated both by central and state government-run public bodies. Most of the education sector in India runs on government funds and there has been no significant contribution of private partners. However, in the past decades new private partners have come forward with the idea of creative learning like Dayan and Anglo Vedic School (DAV), Delhi Public School, Padma Seshadri group, Trust schools (like Sai Educational Trust and Ravi Shankar Educational trust) in addition to the recent introduction of Zee Schools (Pohjola, 2002). The central government regulates the vocational and skill based education in India through National Skill development Council, Ministry of Human resource development (Dept. of School education and Literacy, Dept. of Higher Education), Ministry of Labour and Employment and Director General of Employment and Training (DGET) and several other ministries. These are the regulatory bodies and ministers run by central government for promoting vocational and technical education (Pringle and David, 2005).

Increasing use of computer assisted Learning Technologies (ICT) has been instrumental in general school based education and in technical institutes. However, no such significant technology has been implemented in the vocational and polytechnic institutes (Pringle and David, 2005). Most of the skilled development courses in India at present are limited to
ITIs and ITCs; however the need of the time is to introduce the same among the schools at all the levels ranging from primary to higher secondary schools. In recent past the government has realized the importance this and through the National Skill Development policy with specific focus on developing modular skills (employable skills) that requires practical and need based training and theoretical appraisal.

However, the contribution of these private players has only been for general schooling and technical education like engineering, medical and architecture with little or no major partner in vocation or skill based education (Pohjola, 2002). A major limitation has been the non-facilitating or strict government regulations and provisions affiliating these private partners for imparting education in India (Licker, 2001).

\section{Extending the System of Vocational Education to Schools}

In India School education, higher education in colleges and Universities and technical education like engineering, medicine and architecture form three major axes of educational system. This targeted focus has led to negligence and lack of development among polytechnic institutes and development of skill based education in schools.

The idea of making each individual more economically productive and self-reliant is primarily based on the acquisition of skills which are marketable, employable and industrial (Kuriyan et al., 2006). These courses add-on to a candidate's scope for a broad range of careers, jobs and services with a better choice of jobs. A thorough exposure to different skill based educational and vocational training can be instrumental in this process (Fig. 4) (Kuriyan et al., 2006). A motivation for students from lower economic strata of the society has been the ability to start their career and start earning at an early age through vocational and practical skills (Fig. 4). This helps them to pursue their study along with contribution to the family's income and thus financial limitations do not take their toll on their education anymore (Licker, 2001).

The Industrial Training Institutes (ITIs) and Industrial Training Centers (ITCs) coming under the regulation of Ministry of Labour and employment, govt, of India has been taking steps in promotion and more employability of vocational students. However, the Dept. of School Education under MHRD, Govt of India and Ministry of Labour and Employment need to develop a convergent plattform for introducing vocational and skill based education in schools. This will help to eliminate the non-synchronous presence of the vocational institutes and schools. This can ultimately render the idea of skill development through academic framework of course at schools more possible (Pohjola, 2002) (Fig. 4). 

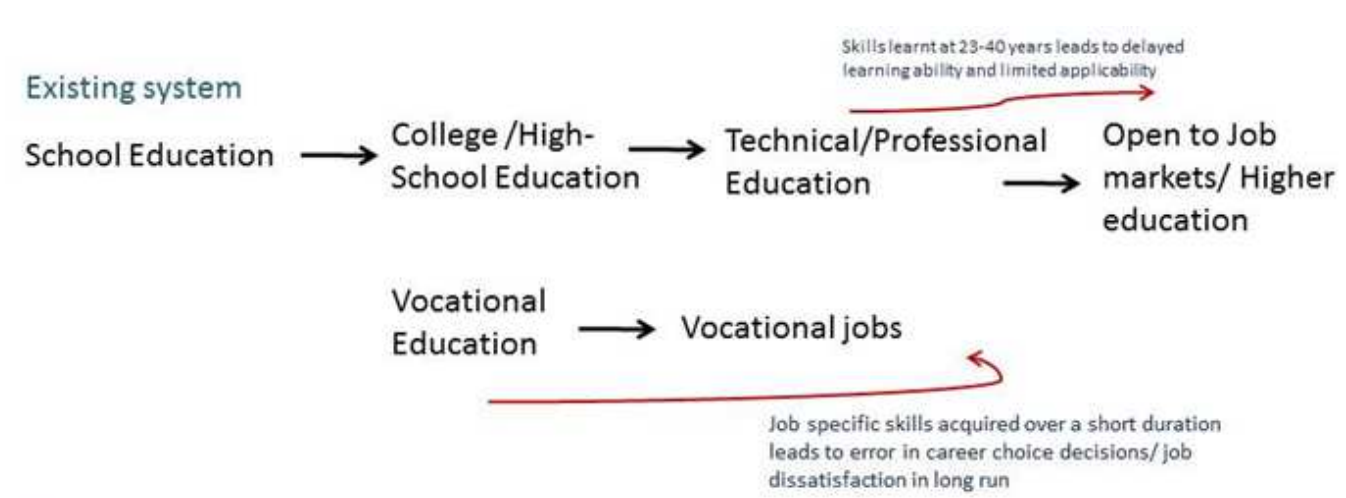

Proposed system

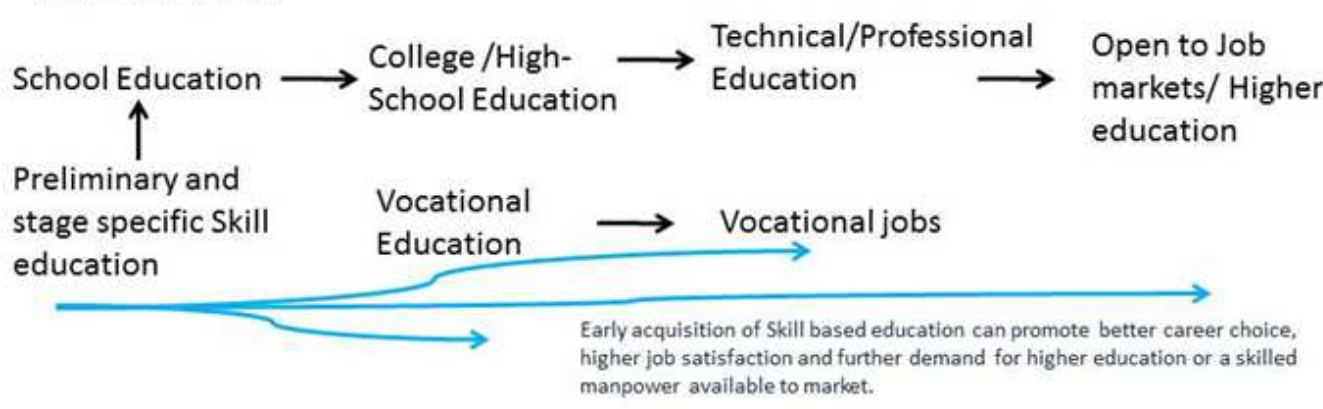

Proposed pipeline for introduction of early skill based education in Schools

Fig. 4. The proposed changes to existing vocation education and integration of an early and precise skill based education in schools of India

The educational curriculum suggested by National Education Policy (NEP) for schools, needs to further emphasize on the introduction of these skill and vocational education. Similar instructions must be passed onto and developed by the state governments to develop skill based education in state regulated schools (Fig. 4). The state government regulated schools need to develop a joint discussion with the central government and other regulatory bodies in relation to the development of skill education in the schools especially in the rural and remote corners of the state that will help to bring down economic self-sufficiency among those people (Rao, 2005).

The existing National Council for Vocation Training (NCVT) needs to find a congruent criterion for developing coordinated curriculum for vocational education among schools.

To manage the financial burden private public partnership and promotion of Corporate Social Responsibility (CSR) activities can be fruitful and calls for more involvement of administrative bodies with such private firms. In addition, introduction of summer schools, internships and seminar based learning and soft skill enhancement during the academic training at schools should be implemented (Rao, 2005).

\section{Discussion}

One of the major challenges in designing an appropriate coursework for skill based education among schools will be the limited infrastructural availability, the lack of skilled and trained teacher body which can ease the simultaneous delivery of general and vocational courses. In the fast evolving age of economic and social development, individual development needs to be equally emphasized upon. This realisation needs to take shape in the form of introduction of vocational and skill based education at early stage during school education and will thus help in building more effective human resource with greater productivity.

\section{Conclusion}

In the long run, early shaping of the human capital can ensure the country's economic boost and thus requires implementation of skill based education at schools. However, the existing infrastructural and financial limitation of schools and polytechnic institutes in ensuring effective delivery of such courses needs to be monitored by government with active participation of private firms. 


\section{Acknowledgement}

The authors would like to acknowledge the Ministry of Human resource development, Government of India for their detailed archiving of documents and policy reports related to skill development in India.

\section{Author's Contributions}

Both the authors have equally contributed to this manuscript.

\section{Conflict of Interest}

The authors declare no conflict of interest with any institution or any funding body for the publication of this paper.

\section{References}

Burrell, J. and K. Anderson, 2008. I have great desires to look beyond my world: Trajectories of information and communication technology use among Ghanaians living abroad. New Media Society, 10: 203-224. DOI: $10.1177 / 1461444807086472$

Burrell, J., 2006a. Internet scamming and the consequences of connectivity in a developing nation. Unpublished Manuscript.

Burrell, J., 2006b. Telling stories of internet fraud: How word of mouth shapes Internet usein Accra, Ghana. Unpublished Manuscript.

Dhawan, V., 2004. Critical success factors for rural ICT projects in India: A study of n-Logue projects at pabal and Baramati. MSc. Thesis, Shailesh Mehta School of Management, Indian Institute of Technology, Bombay.

Haseloff, A.M., 2005. Cybercafés and their potential as community development tools in India. J. Community Inform., 1: 53-64.

Kaushik, P.D. and N. Singh, 2004. Information technology and broad-based development: Preliminary lessons from North India. World Develop., 32: 591-607.

DOI: 10.1016/j.worlddev.2003.11.002
Kiri, K. and D. Menon, 2006. For profit rural kiosks in India: Achievements and challenges. Inform. Dev.

Kumar, R., 2004. Social governance and economic impact assessment of information and communication technology interventions in rural India. MSc. Thesis, Urban Studiesand Planning, Massachusetts Institute of Technology.

Kuriyan, R., K. Toyama and I. Ray, 2006. Integrating social development and financial sustainability: The challenges of rural computer kiosks in Kerala. Proceedings of the International Conference on Information and Communication Technologies and Development, May 25-26, IEEE Xplore Press, Berkeley, CA, pp: 121-130. DOI: 10.1109/ICTD.2006.301849

Lee, S., 1999. Private uses in public spaces a study of an internet Café. New Media Society, 1: 331-350. DOI: $10.1177 / 14614449922225618$

Licker, P.A., 2001. A gift from the gods? Components of information technology fatalism, determinism in several cultures. Electr. J. Inform. Syst. Dev. Countr., 7: 1-11.

NSDC, 2005. Human resource and skill requirements in the education and skill development services sector: study on mapping of human resource skill gaps in India till 2022. National Skill Development Corporation, Govt of India.

Pohjola, M., 2002. The new economy in growth and development. Oxf. Rev. Economic Policy, 18: 380-396. DOI: 10.1093/oxrep/18.3.380

Pringle, I. and M.J.R. David, 2005. Rural community ICT applications: The kothmale model.

Rao, S.S., 2005. Bridging digital divide: Efforts in India. Telemat. Inform., 22: 361-375.

DOI: 10.1016/j.tele.2005.01.007 